\title{
Tensile Properties of Cast Alloy IN625 in Relation to $\delta$ Phase Precipitation
}

\author{
Yi-Qiang $\mathrm{Mu}^{1,2} \cdot$ Chang-Shuai Wang $^{1} \cdot$ Wen-Long Zhou ${ }^{2} \cdot$ Lan-Zhang Zhou ${ }^{1}$
}

Received: 26 March 2018/Revised: 22 April 2018/Published online: 27 June 2018

(C) The Chinese Society for Metals and Springer-Verlag GmbH Germany, part of Springer Nature 2018

\begin{abstract}
The relationship between the tensile properties and $\delta$ (delta) phase precipitation in cast alloy IN625 was investigated in this paper. Although the influences of $\delta$ phase on the mechanical properties have been pointed out in our previous work, the relationship is still not directly determined due to the coexistence of $\gamma^{\prime \prime}$ (gamma double prime) and $\delta$ precipitates. In order to exclude the effect from $\gamma^{\prime \prime}$ phase, various fractions of $\delta$ precipitates with few $\gamma^{\prime \prime}$ precipitates were obtained by a set of experimental alloys aging at $750{ }^{\circ} \mathrm{C}$, and tensile tests were conducted in parallel. The results showed that both yield strength and ultimate tensile strength increased nearly in linear with increasing $\delta$ phase fraction, while the elongation was relatively and limitedly affected by $\delta$ precipitation when the area fraction of $\delta$ phase was above $10 \%$.
\end{abstract}

Keywords $\delta$ Phase $\cdot$ Cast alloy IN625 · Tensile properties · Advanced ultra-supercritical (AUSC)

\section{Introduction}

Pulverised coal combustion (PCC) power plant dominates the power industry and will continue to maintain their superiority for the foreseeable future. To meet the demand for clean and affordable energy, an increase in the operating efficiency of PCC power plants is therefore necessary. One of the most effective ways for this is to increase the steam parameters. Advanced ultra-supercritical (AUSC) power plants are, therefore, being developed with the aim of operating with a steam temperature of $700-760{ }^{\circ} \mathrm{C}$ and pressure of $27.6-34.5 \mathrm{MPa}$. Such service conditions require the use of nickel alloys [1-3]. IN625 (UNS N06625) is selected as a candidate material for its good high strength, excellent fabricability and outstanding corrosion resistance [4-9]. There are many reports about wrought alloy IN625 [7-22], while the studies on cast alloy IN625 (N26625), which is very needed for the large

Available online at http://link.springer.com/journal/40195

Lan-Zhang Zhou

1zz@imr.ac.cn

1 Institute of Metal Research, Chinese Academy of Science, Shenyang 110016, China

2 School of Materials Science and Engineering, Dalian University of Technology, Dalian 116024, China castings in A-USC power plants [4], are scarce [23]. Further, $\delta$ phase is found to precipitate easily after long-term aging at the service temperature of A-USC power plants $\left(700-760{ }^{\circ} \mathrm{C}\right)$ in cast alloy IN625 [23]. Therefore, the study on the relationship between the tensile properties and $\delta$ phase precipitation in cast alloy IN625 is needed for its application in A-USC power plants.

It has been established that $\delta-\mathrm{Ni}_{3} \mathrm{Nb}$ phase plays an important role in the mechanical properties by many former researchers. The work by Ye et al. [24] and Rao et al. [25] indicated that the presence of the $\delta$ phase decreased the yield and tensile strengths in wrought alloy IN718 (N07718) due to the corresponding depletion of the $\gamma^{\prime \prime}$ phase. In addition, Valle et al. [26] proved that the presence of the $\delta$ phase decreased the yield and tensile strengths of wrought alloy IN718 but has a beneficial effect on the rupture ductility. However, the precipitation of $\delta$ phase led to an increase in strength and loss in ductility in wrought alloy IN625 [27-30]. A similar conclusion was drawn in our previous work on cast alloy IN625 [23]. The abovementioned works [23-30] have been focused on the effect of $\delta$ phase on mechanical properties, but no consistent conclusions were put forward by far [23-30]. Moreover, the relationship between the tensile properties and the fraction of $\delta$ phase is still not determined directly due to the coexistence of $\gamma^{\prime \prime}$ phase. Therefore, the relationship between the tensile properties and the fraction of $\delta$ phase is 
worthwhile of further study. To eliminate the effect of $\gamma^{\prime \prime}$ phase on strength, a set of experimental alloys were aging at $750{ }^{\circ} \mathrm{C}$ to obtain different fractions of $\delta$ phase precipitation with few $\gamma^{\prime \prime}$ phases and further to directly determine the relationship between $\delta$ phase fraction and tensile properties in cast alloy IN625.

\section{Experimental}

Table 1 [23] lists the nominal compositions of the experiment alloys used in this study. As mentioned in our previous work [23], the precipitation of $\delta$ phase in cast alloy IN625 is strongly affected by $\mathrm{Nb}$ content. Therefore, the different fractions of $\delta$ phase precipitation in cast alloy IN625 are excepted to be obtained by changing $\mathrm{Nb}$ content.

The experimental alloys were prepared by vacuum induction. The alloys were solution-treated at $1200{ }^{\circ} \mathrm{C}$ for $1 \mathrm{~h}$ followed by water cooling and then aged at $750{ }^{\circ} \mathrm{C}$ for up to $17,000 \mathrm{~h}$.

Metallographic samples were prepared for observation in a JSM-6301F scanning electron microscope (SEM). The identification of $\delta$ phase was performed using a TECNAI G2 and F30 transmission electron microscope (TEM). Tensile tests at $700{ }^{\circ} \mathrm{C}$ were carried out on a Shimadzu AG-250KNE test machine. The cylindrical, threaded tensile test rods with a gauge length of $\Phi 5 \mathrm{~mm} \times 25 \mathrm{~mm}$ machined from the thermally exposed bars were prepared as standard GB/T 4338-2006. Each datum is an average of at least two tensile tested values. The dislocation substructure in the aged experimental alloys after tensile test was observed by TEM.

\section{Result and Discussion}

Figure 1 shows the microstructures of the $\mathrm{Nb}$ series of alloys (named as alloy $3.15 \mathrm{Nb}, 3.8 \mathrm{Nb}$ and $4.5 \mathrm{Nb}$ ) after aging at $750{ }^{\circ} \mathrm{C}$ for up to $17,000 \mathrm{~h}$. As shown in Fig. 1, a lot of needle-like $\delta$ phases precipitated in the $\mathrm{Nb}$ series of alloys after aging at $750{ }^{\circ} \mathrm{C}$ for $1000 \mathrm{~h}$, while few $\gamma^{\prime \prime}$ phase precipitates were observed. $\delta$ Phase was identified based on the TEM results (Fig. 2). The amount of $\delta$ phase precipitation increased obviously with increasing $\mathrm{Nb}$ content.

Table 1 Nominal compositions of the experimental alloys (wt\%) [23]

\begin{tabular}{llllll}
\hline Alloy & $\mathrm{Nb}$ & $\mathrm{Mo}$ & $\mathrm{Cr}$ & $\mathrm{C}$ & $\mathrm{Ni}$ \\
\hline $3.15 \mathrm{Nb}$ & 3.15 & 9 & 21.5 & 0.05 & Bal. \\
$3.8 \mathrm{Nb}$ & 3.8 & 9 & 21.5 & 0.05 & Bal. \\
$4.5 \mathrm{Nb}$ & 4.5 & 9 & 21.5 & 0.05 & Bal. \\
\hline
\end{tabular}

Here, it is worth mentioning that the $\gamma$-matrix appeared to be free of any other phase besides the scattered MC carbides in cast alloy IN625 before aging treatment [23].

After prolonged aging at $750{ }^{\circ} \mathrm{C}$ for up to $17,000 \mathrm{~h}$, the amount of $\delta$ phase remained an increase with increasing $\mathrm{Nb}$ content. Meanwhile, the amount of $\delta$ phase increased with the aging time for all the alloys. It was worth noting that few $\gamma^{\prime \prime}$ phase precipitates were observed after aging at $750{ }^{\circ} \mathrm{C}$ for up to $17,000 \mathrm{~h}$. As expected, various amounts of $\delta$ phase with few $\gamma^{\prime \prime}$ phases were obtained by changing aging time and $\mathrm{Nb}$ content. In compared with our previous work, $\mathrm{Nb}$ achieved the same effect on $\delta$ phase precipitation when after aging at 750 and $700{ }^{\circ} \mathrm{C}$ [23]. Increasing $\mathrm{Nb}$ content led to an increase in $\delta$ phase precipitation.

Figure 3 shows the area fraction of $\delta$ phase plotted as a function of $\mathrm{Nb}$ content and aging time. The area fraction of $\delta$ phase was measured from the SEM micrographs using Image-Pro Plus 6.0 software (Media Cybernetics Inc.). It was visualized that the area fraction of $\delta$ precipitation after aging at $750{ }^{\circ} \mathrm{C}$ increased obviously with increasing $\mathrm{Nb}$ content at each given time. Moreover, the area fraction of $\delta$ phase precipitation in each alloy also increased with the aging time and globally finally reached a steady at longer duration. The first and the last to reach the saturation level were alloy $4.5 \mathrm{Nb}$ and $3.15 \mathrm{Nb}$, respectively. This indicates that adding more $\mathrm{Nb}$ content will accelerate the precipitation of $\delta$ phase. It was also noticed that the area fraction of $\delta$ phase precipitation increased significantly with increasing temperature from 700 to $750{ }^{\circ} \mathrm{C}$ [23]. This suggests that $\delta$ phase precipitation is sensitive to the aging temperature.

In this work, the values of the precipitation kinetics parameters were calculated to describe the effect of $\mathrm{Nb}$ on $\delta$ phase precipitation intuitively. At a given aging temperature, the relationship between the weight percentage of $\delta$ phase, $W_{\delta}$, and aging time can be described by the Avrami equation: $W_{\delta}=W_{\mathrm{s}}\left[1-\exp \left(-\alpha \cdot t^{n}\right)\right]$, where $n$ is a constant that depends on the nucleation and growth of $\delta$ phase, $\alpha$ is the rate of $\delta$ precipitation, and $W_{\mathrm{s}}$ is the saturation level for the $\delta$ precipitation [31]. Here, $W_{\delta}$ and $W_{\mathrm{s}}$ are replaced by $A_{\delta}$ (the area percentage of $\delta$ phase) and $A_{\mathrm{s}}$ (the saturation level for the $\delta$ precipitation), respectively. The values of the precipitation kinetics parameters obtained by fitting this equation to the experimental data (Fig. 4) are listed in Table 2. The effect of $\mathrm{Nb}$ on $\delta$ phase precipitation can be approximately described by the values of $n$ and $\alpha$. It is observed that as the content of $\mathrm{Nb}$ increases, the value of $\alpha$ increases while the value of $n$ decreases. This indicates that the precipitation rate of $\delta$ phase increases and the time for precipitation is shortened. The more $\mathrm{Nb}$ content leads to a faster rate of the precipitated phase, thus reducing the time to reach the saturation level. The effect of $\mathrm{Nb}$ on $\delta$ phase precipitation can be 

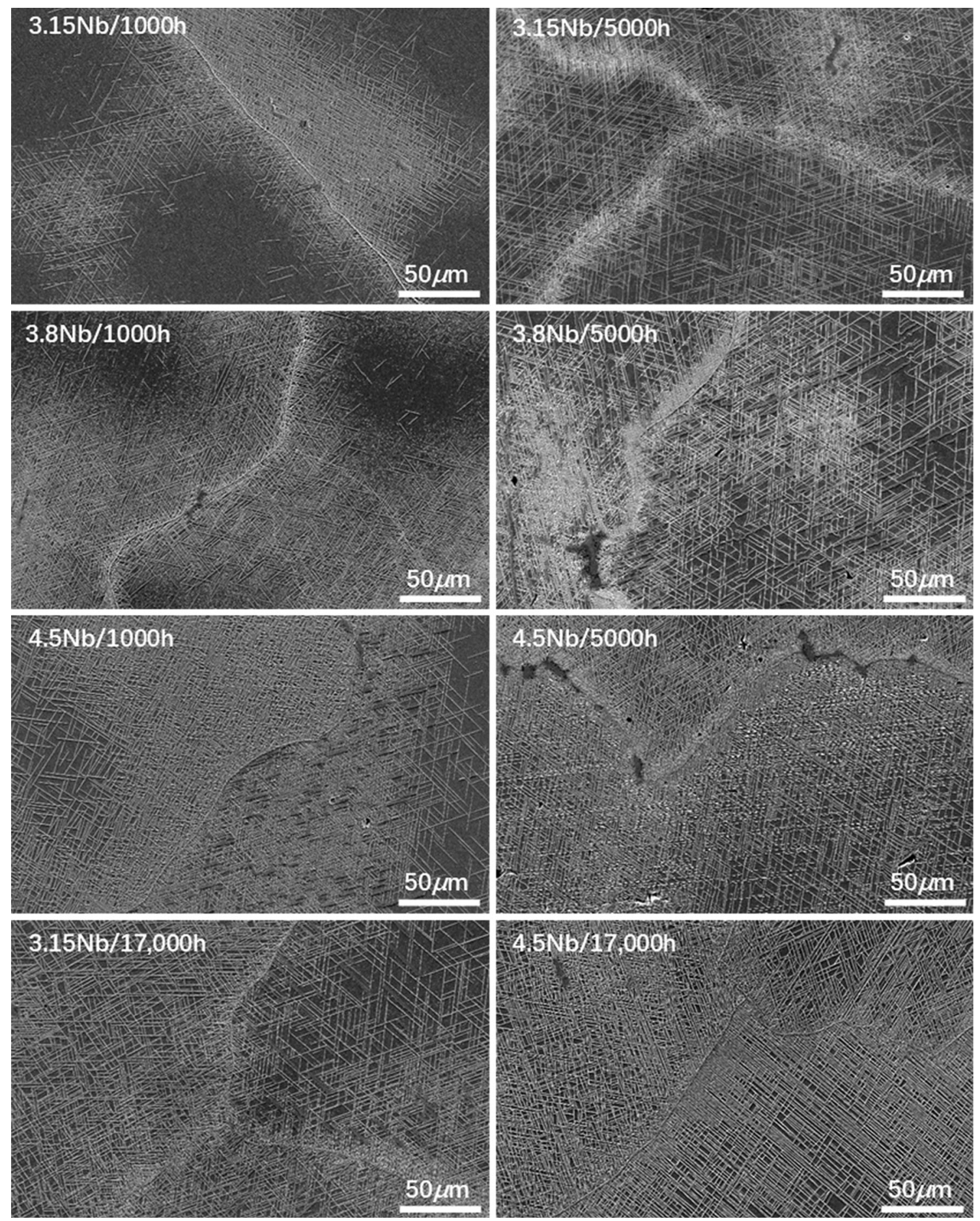

Fig. 1 SEM micrographs of $\delta$ phases in the $\mathrm{Nb}$ series of alloys after aging at $750{ }^{\circ} \mathrm{C}$ for 1000,5000 and $17,000 \mathrm{~h}$

attributed to its influence on the degree of $\mathrm{Nb}$ segregation. The degree of $\mathrm{Nb}$ segregation increased with increasing $\mathrm{Nb}$ content [23]. Therefore, more niobium could segregate at excess vacancy, dislocations and extrinsic stacking faults in the $\gamma$ matrix. This brought out the reduction in the critical nucleus free energy and further promoted the precipitation of $\delta$ phase [23, 32]. Hence, the effect of $\mathrm{Nb}$ on $\delta$ phase is further confirmed by calculating the values of the precipitation kinetics parameters in the present work.

Figure 5 presents the tensile properties at $700{ }^{\circ} \mathrm{C}$ of the $\mathrm{Nb}$ series of alloys as-heat treated [23] and after aging at $750{ }^{\circ} \mathrm{C}$ for up to $5000 \mathrm{~h}$. It is observed that the yield strength (YS), ultimate tensile strength (UTS) and elongation (EL) after solution-treated appeared to be not 


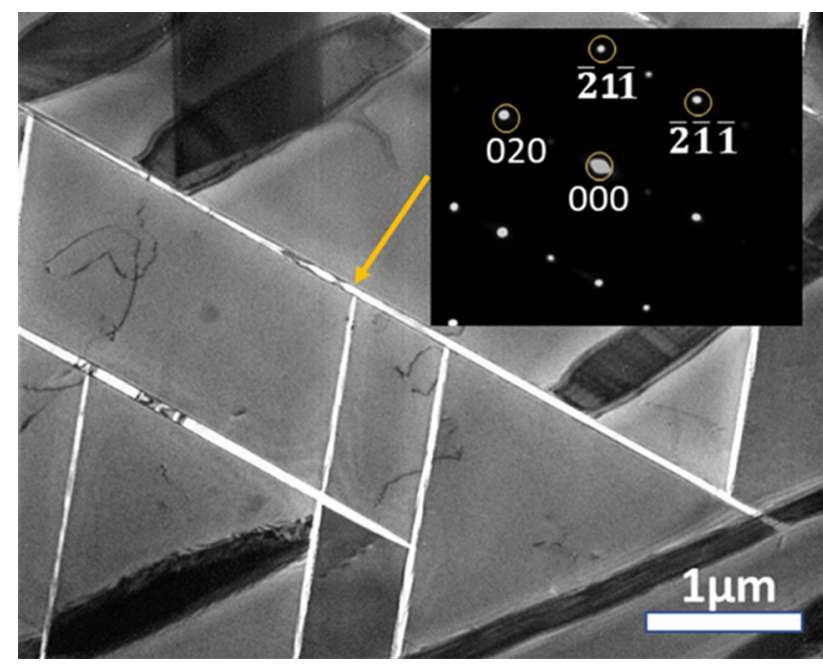

Fig. 2 TEM image of the $\delta$ phases and corresponding selected-area electron diffraction pattern (inset)

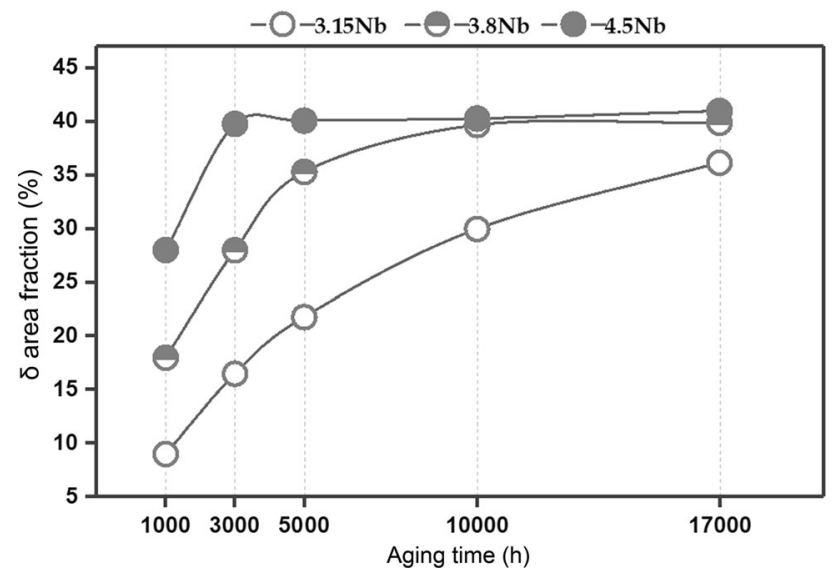

Fig. $3 \delta$ Phase area fraction evolution as a function of aging time and $\mathrm{Nb}$ content after aging at $750{ }^{\circ} \mathrm{C}$

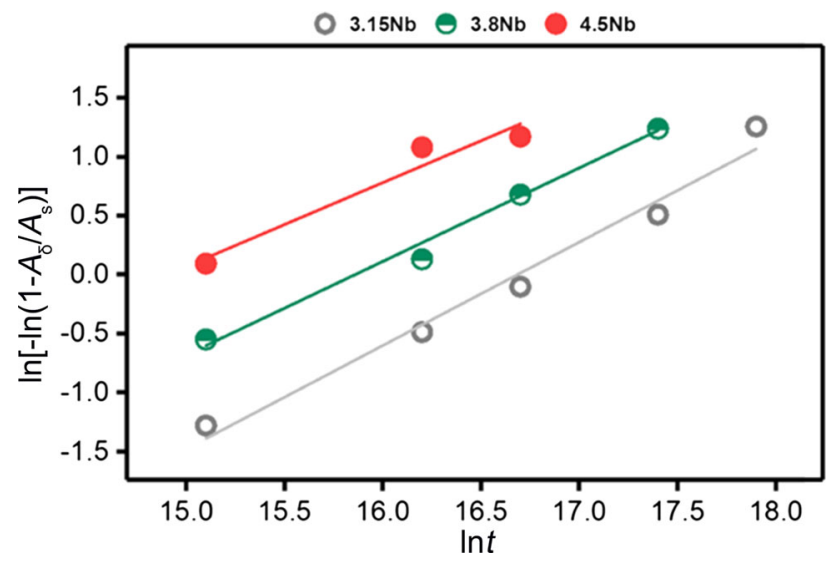

Fig. 4 Relationship between $\ln \left[-\ln \left(1-A_{\delta} / A_{\mathrm{s}}\right)\right]$ and $\ln t$

sensitive to the varied additions of $\mathrm{Nb}$. However, both YS and UTS increased considerably with the $\mathrm{Nb}$ content after
Table 2 Parameters for precipitation kinetics of $\delta$ phase

\begin{tabular}{lll}
\hline Alloy & $\alpha$ & $N$ \\
\hline $3.15 \mathrm{Nb}$ & $4.47 \times 10^{-7}$ & 0.876 \\
$3.8 \mathrm{Nb}$ & $3.51 \times 10^{-6}$ & 0.792 \\
$4.5 \mathrm{Nb}$ & $2.57 \times 10^{-5}$ & 0.710 \\
\hline
\end{tabular}

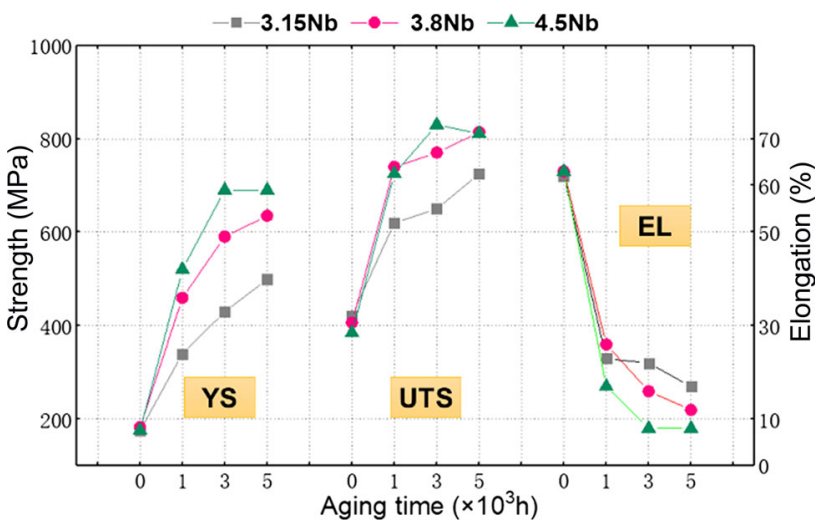

Fig. 5 Tensile properties at $700{ }^{\circ} \mathrm{C}$ of the $\mathrm{Nb}$ series of alloys aged at $750{ }^{\circ} \mathrm{C}$ for $0 \mathrm{~h}$ (as-solution-treated), 1000, 3000 and $5000 \mathrm{~h}$

aging at $750{ }^{\circ} \mathrm{C}$ for up to $5000 \mathrm{~h}$. This is similar to the effect of $\mathrm{Nb}$ on strength in cast alloy IN625 after aging at $700{ }^{\circ} \mathrm{C}$ [23]. As opposed to the increase in strength, the values of $\mathrm{EL}$ decreased with increasing $\mathrm{Nb}$ content. In general, prolonged aging at $750{ }^{\circ} \mathrm{C}$ resulted in the increase in strength and the decrease in ductility, but the nearly same tensile properties of alloy $4.5 \mathrm{Nb}$ after aging at $750{ }^{\circ} \mathrm{C}$ for 3000 and $5000 \mathrm{~h}$.

As mentioned above, $\delta$ phase precipitation can be considered as the only change in microstructure due to few $\gamma^{\prime \prime}$ phase precipitation after aging at $750{ }^{\circ} \mathrm{C}$. This suggests that the above-mentioned mechanical property changes are closely related to the $\delta$ phase precipitation. To better document the relation between $\delta$ phase precipitation and tensile properties, YS, UTS, and EL variations were plotted again as a function of the $\delta$ phase area fraction (Fig. 6). It can be observed in Fig. 6a, b that both YS and UTS increased with increasing fraction of $\delta$ phase in cast alloy IN625. $\delta$ Phase has played the same role in the strength in cast and wrought alloy IN625 [23, 27-30]. As few $\gamma^{\prime \prime}$ precipitates existed, the relationship between $\delta$ phase precipitation and tensile properties has been directly observed in the present work. As shown in Fig. 6a, b, both YS and UTS increased almost in linear with the $\delta$ phase area fraction for alloy $3.15 \mathrm{Nb}, 3.8 \mathrm{Nb}$ and $4.5 \mathrm{Nb}$, respectively. The linear relationship was still borne out when the full results of all alloys were considered together. This has not been pointed out in former reports [23-30]. The abovementioned suggests that $\delta$ phases serve as a strong phase in cast alloy IN625, which is confirmed by TEM (Fig. 6d). As shown in Fig. 6d, the dislocation slip has been pinned by $\delta$ 

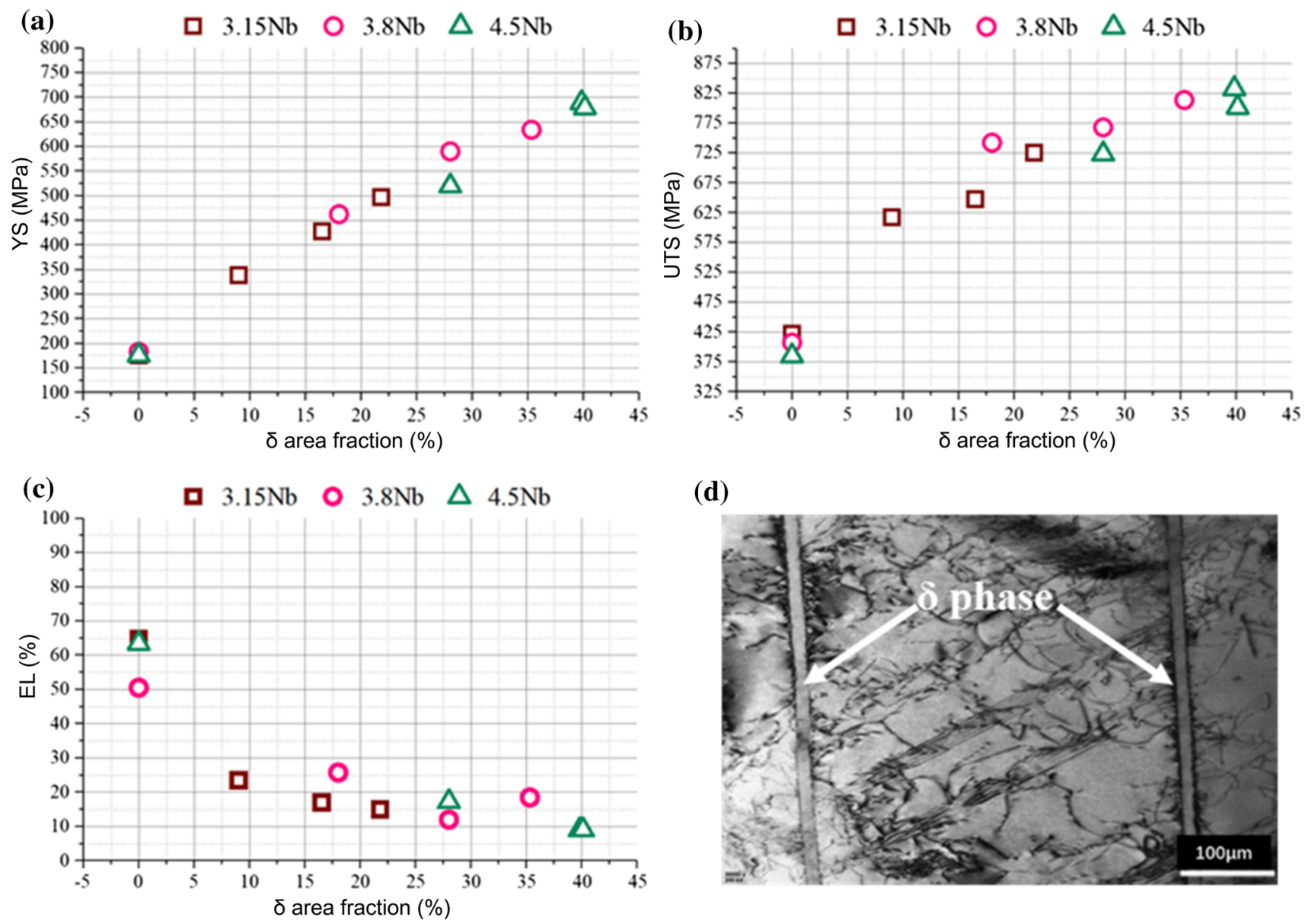

(d)

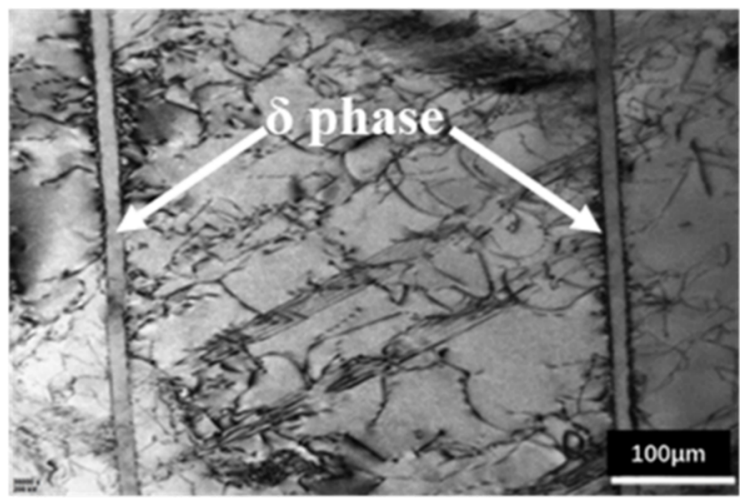

Fig. 6 a YS, b UTS, c EL variations plotted as a function of the $\delta$ phase area fraction, $\mathbf{d}$ the dislocation substructure around $\delta$ phase in the aged experimental alloys after tensile tests

phases. This resulted in the stress concentration around $\delta$ phase when the motion of dislocation was prevented $[23,33]$. As for elongation, its values decreased with increasing amount of $\delta$ phases (Fig. 6c). It is interesting to find that there are two factors for the decrease in elongation. Firstly, the precipitation of $\delta$ phases after aging for $1000 \mathrm{~h}$ resulted in a sharp decrease in the elongation of all alloys. Secondly, although the elongation remained to decrease with the continuous precipitation of $\delta$ phase after prolonged aging, the majority of the elongation after aging for $1000-5000 \mathrm{~h}$ is between $10 \%$ and $25 \%$. Therefore, it can be directly concluded that the strength of the alloys is enhanced by $\delta$ precipitation and the increasing $\delta$ phase fractions have a limited effect on elongation when the area fraction of $\delta$ phase is above $10 \%$. As for the nearly same tensile properties of alloy $4.5 \mathrm{Nb}$ after aging at $750{ }^{\circ} \mathrm{C}$ for 3000 and $5000 \mathrm{~h}$, it can be attributed to their same area fractions of $\delta$ phase precipitation.

\section{Conclusion}

To directly reveal the relationship between tensile properties and $\delta$ phase precipitation in cast alloy IN625, various fractions of $\delta$ phase with few $\gamma^{\prime \prime}$ phase have been obtained by changing $\mathrm{Nb}$ content and aging time. The relationship between tensile properties and $\delta$ phase precipitation has been directly determined in this work. Both yield strength and ultimate tensile strength increase nearly in linear with the $\delta$ phase area fraction. $\delta$ Phase serves as a strengthening phase in cast alloy IN625, as the tensile strength of cast alloy IN625 is improved by $\delta$ phase precipitation without sacrificing much ductility when the area fraction of $\delta$ phase is above $10 \%$.

Acknowledgements This work was financially supported by the National Key Research and Development Program of China (No. 2017YFB0305204) and the National Natural Science Foundation of China (No. 51571191). 


\section{References}

[1] R. Zhou, L. Zhu, Y. Liu, Z. Lu, L. Chen, X. Ma, J. Mater. Sci. 52, 6161 (2017)

[2] X. Song, L. Tang, Z. Chen, R. Zhou, J. Mater. Sci. 52, 4587 (2017)

[3] K. Nicol, Status of Advanced Ultra-Supercritical Pulverised Coal Technology (IEA Clean Coal Center, London, 2013)

[4] P.D. Jablonski, J.A. Hawk, C.J. Cowen, P.J. Maziasz, JOM 64, $271(2012)$

[5] A. Nair, S. Kumanan, in Proceedings of the International Conference on Advances in Production and Industrial Engineering 2015, NIT Trichy, India, 2015

[6] F. Abe, Engineering 1, 211 (2015)

[7] N. Lückemeyer, H. Kirchner, H. Almstedt, in Proceedings of ASME turbo expo 2012, Copenhagen, Denmark, June 11-15, 2012

[8] J.A. Siefert, J.P. Shingledecker, J.N. DuPont, S.A. David, Sci. Technol. Weld. Joi. 21, 397 (2016)

[9] D. Castello, B. Rolli, A. Kruse, L. Fiori, Energies 10, 1734 (2017)

[10] S. Floreen, G.E. Fuchs, W.J. Yang, in The metallurgy of alloy 625. Superalloys 718, 625 and Various Derivatives, TMSAIME, Warrendale, 1994, pp. 13-37

[11] I.J. Moore, J.I. Taylor, M.W. Tracy, M.G. Burke, E.J. Palmiere, Mater. Sci. Eng., A 682, 402 (2017)

[12] L.M. Suave, D. Bertheau, J. Cormier, P. Villechaise, A. Soula, Z. Hervier, J. Laigo, in MATEC Web of Conferences, EUROSUPERALLOYS 2014-2 ${ }^{\text {nd }}$ European Symposium on Superalloys and their Applications, EDP Sciences, 2014

[13] E.A. Lass, M.R. Stoudt, M.E. Williams, M.B. Katz, L.E. Levine, T.Q. Phan, Metall. Mater. Trans. A 48, 5547 (2017)

[14] L.M. Suave, J. Cormier, P. Villechaise, A. Soula, Z. Hervier, D. Bertheau, J. Laigo, Metall. Mater. Trans. A 45, 2963 (2014)
[15] M.D. Mathew, K.B.S. Rao, S.L. Mannan, Mater. Sci. Eng., A 372, 327 (2004)

[16] J.S. Kim, H.W. Lee, Int. J. Electrochem. Sci. 10, 6454 (2015)

[17] S. Malej, J. Medved, B.Š. Batič, F. Tehovnik, M. Godec, Metalurgija 56, 319 (2017)

[18] X.J. Di, X.X. Xing, B.S. Wang, Acta Metall. Sin. 50, 323 (2014) (in Chinese)

[19] M. Sundararaman, P. Mukhopadhyay, S. Banerjee, MTA 19, 453 (1988)

[20] D.R. Muzyka, G.N. Maniar, Metals. Eng. Quart. 9, 23 (1969)

[21] A. Kumar, K.V. Rajkumar, T. Jayakumar, B. Raj, B. Mishra, J. Nucl. Mater. 350, 284 (2006)

[22] Y.T. Ding, Y.B. Gao, Z.Y. Dou, X. Gao, D.X. Liu, Z. Jia, Acta Metall. Sin. 53, 695 (2017). (in Chinese)

[23] Y.Q. Mu, C.S. Wang, W.L. Zhou, L.Z. Zhou, Metals 8, 86 (2018)

[24] N.Y. Ye, M. Cheng, S.H. Zhang, H.W. Song, H.W. Zhou, P.B. Wang, J. Iron. Steel Res. Int. 22, 752 (2015)

[25] G.A. Rao, M. Kumar, M. Srinivas, D.S. Sarma, Mater. Sci. Eng., A 355, 114 (2003)

[26] L.C.M. Valle, L.S. Araújo, S.B. Gabriel, J. Dille, L.H. Almeida, J. Mater. Eng. Perform. 22, 1512 (2013)

[27] F. Xu, Y. Lv, Y. Liu, B. Xu, P. He, Phys. Procedia 50, 48 (2013)

[28] D.B. Witkin, P. Adams, T. Albright, in Proceedings of the SPIE LASE, International Society for Optics and Photonics, 2015, 93530B-93530B-12

[29] A. Chatterjee, G. Sharma, R. Tewari, J.K. Chakravartty, Metall. Trans. A 46, 1097 (2015)

[30] V. Shankar, K.B.S. Rao, S.L. Mannan, J. Nucl. Mater. 288, 222 (2001)

[31] W.C. Liu, M. Yao, Z.L. Chen, Metall. Trans. A 30, 31 (1999)

[32] W.C. Liu, M. Yao, Z.L. Chen, S.G. Wang, J. Mater. Sci. 34, $2583(1999)$

[33] A.C. McLaren, J.A. Retchford, Phys. Stat. Sol. (b) 33, 657 (1969) 